\title{
ISABEL, ROSARIO Y MARUXA: EL DRAMA DE LA MATRIA, PATRIA MEXICANA EN FEMEMINO
}

\author{
ISABEL, ROSARIO AND MARUXA: THE DRAMA OF MATRIA, MEXICAN PATRIA \\ IN FEMENINE
}

Lilia Granillo Vázquez

Universidad Autónoma Metropolitana, Ciudad de México

\section{Resumen:}

Esta investigación descubre una nuena manera de contar la historia nacional, la escritura dramática con óptica de género, mirada de mujer. Las dramaturgas, dos mexicanas y dos españolas, abordan el drama de la patria, desde diversos géneros, estilos y épocas. Teatro con preocupaciones femeninas y feministas, y anhelos de paz, de convivencia pacífica, de comunidad armoniosa, de denuncia de la desigualdad. Comedia, farsa, tragedias, tragicomedias que transitan por el corredor cultural Iberoamericano y su historia violenta, de violencia contra las mujeres.

\section{Palabras clave:}

Dramaturgas mexicanas, violencia de género, Escritoras hispanomexicanas, nacionalismo mexicano.

\section{Abstract:}

This paper revisits the works of 4 female playwrights who in diverse genders, styles and periods represent the drama of $\mathrm{La}$ Patria, motherland. Theater with feminine and feminist concerns, about peace, peaceful coexistence, a sense of community, and inequality complaints. Comedy, farce, tragedies, and melodrama move across the Iberoamerican cultural corridor and its violent history, and also violence against women.

\section{KeYWORDS:}

Mexican playwrights, gender violence, Hispanomexican Women Writers, Mexican nationalism. 


\section{EL DRAMA DE LA MATRIA, EXTRAÑO Y SINGULAR HÍBRIDO}

Eva: ... Desde hace siglos he soñado con contarle a alguien la verdadera historia de la pérdida del Paraíso, no esa versión para retrasados mentales que ha usurpado a la verdad. (Castellanos, 1986: 47)

Revisar la presencia, en México, de las escritoras de obras de teatro y estudiar sus escrituras, es percatarse de la preocupación de las mujeres, diversa de los intereses masculinos. Estas preocupaciones van desde los intereses domésticos, de casa, las identidades sociales, comunitarias. Se trata de "Escribir para reinventarse", postulado de una gran narradora del siglo XX (Domecq, 1994: 26). Acaso sea cierto que en literatura se trasluce siempre la biografía, la autobiografía, la historia propia de quien escribe, aquello de "Todo discurso literario es una extensión del nombre propio" (Custodio 2000: 9) los personajes femeninos creados por ellas, las escenas, los conflictos, sus diálogos, revelan, como se verá en esta investigación, rasgos socioculturales que intentan trazar la historia nacional, pero con mirada de mujer. Asegura Custodio, escritora mexicana de raigambre española, que "Sin duda, los re-cuentos son como en las propias vidas de las mujeres: cíclicos, o sea con "subes y bajas", vueltas, retornos, como si gestarán sobre sí mismas, una vida propia (Op. Cit. 10) ". Y quien lo dice habla desde la pertenencia a una familia de Teatro, familia intercultural, trasatlántica, entre México y España. Su padre, Álvaro Custodio, que nació en Écija, España, en 1912, llegó a México en 1944, tras una estancia en Cuba. Fundó primero la compañía "Teatro Español de México", que estrenó La Celestina adaptada, para años después convertirse en la oficial compañía "Teatro Clásico de México", donde se representaría desde Hamlet hasta la muy mexicana Moctezuma II de Sergio Magaña, o El regreso de Quetzalcoatl, obra del mismísimo Álvaro, exiliado republicano que había sido del círculo de García Lorca, comunista. Isabel, a quien cito, mujer de letras también, ostenta los derechos heredados por el guión de Aventurera, guión cienematográfico muy exitoso, de la llamada Ëpoca de Oro del Cine Mexicano, trasladado luego al Teatro de Revista, Music Hall o Comedia Musical, que sigue representandóse en la actualidad, es madre de Ximena Escalante, también dramaturga. Brianda Domecq, nacida en Estados Unidos, pero de linaje español, se desarrolló y maduró en Ciudad de México, y vive desde la década pasada, en España, es también una escritora trasatlántica, iberoamericana, "extraño y singular híbrido".

El universo representado por Isabel Prieto, Rosario Castellanos y Maruxa Vilalta, 3 escritoras, una mexicanas que visitaron o vivieron en España; otras dos nacidas en España, pero cuya dramaturgia se desarrolló y maduró en suelo mexicano, evoca la discusión inacabada en torno a "México y lo mexicano". 
Pero, sobretodo, con intereses de género, con sororidad, proporcionando los andamio, o acaso las cortinas, sábanas y toallas de las casas de mujeres, de la Ciudad de las Damas, como nos instigara Christine de Pisan. Así que la apuesta es dramatizar los orígenes con visión de futuro; y ello con mirada crítica hacia la historia oficial, la historia escrita por los protagonistas, los héroes y sus intereses por dominar el espacio público.

En personajes, escenas, conflictos y diálogos, las dramaturgas revisadas aquí, hayan o no nacido en México, se preguntan por la tierra, la comunidad, su lugar en el mundo, la desventajosa situación de las mujeres. La teatralidad femenina -y a veces la masculina de lo femenino--, se centra en las relaciones entre hombres y mujeres: el cuestionamente feminista, la inconformidad, lucha pacífica por la liberación femenina. Eso, sin permanecer ajena a su tiempo. Se transforma para englobar la contemporaneidad, con ese rasgo distintivo de lo nacional.

En la representación teatral es donde, desde tiempos prehispánicos, se perciben las desventajas del género en este país. Cuando se hablaban sólo lenguas originarias, se perciben las diferencias, las desventajas de género, más allá de clase, etnia, lenguas, creencias religiosas. ¿Qué otro rasgo distintivo define lo nacional? La historia compartida, el pasado que desde el presente se lanza al futuro. Representar al pueblo y ocupar sus espacios escénicos sigue practicándose, viviendose en las comunidades mexicanas, en el centro y la periferia. Esta búsqueda y vivencia de una cultura desde las antigüedades mexicanas o las grecolatinas, hasta lo contemporáneo local (lo mexicano), global (lo trasatlántico, lo iberoamericano) no es mermamente "rescate antropológico de "nuestras raíces". Es a la vez herramienta y pensamiento crítico que intenta, explicar y explicarse la realidad contemporánea para ubicarse en ella. Este trabajo es un acercamiento al " ...impacto de una de las influencias culturales que toman parte de ese extraño y singular híbrido que es el pueblo mexicano." (Prieto y Muñoz, 2008: 1)

Isabel Prieto de Landázuri, nacida en España, pero dramaturga mexicana, con su Lirio entre zarzas inicia este catálogo de mujeres que aman la tierra y sus habitantes, y ven con horror la guerra y las desavenencias domésticas, las estériles batallas de los hombres por las mujeres de otros. Sigue Rosario Castellanos cuya farsa, El Eterno Femenino, cuestiona, desafía el relato histórico patriarcal que somete mujeres al yugo masculino. Luego Elena Garro, la gran figura que emerge desde el cautiverio de sombras al cual Octavio Paz intentó relegarla. Elena deslumbra a la Matria con su gigantesca comprensión del drama mexicano, sea éste matar a sus heroes en Felipe Angeles o la odiosa tradición de raptar y violar a sus mujeres en Los perros. Cierra esta tretalogía del México democrático, la recientemente fallecida (2014), Maruxa Vilalta, nacida española tambien, pero de obra mexicana que invita a mirarse en el espejo y 
verlo todo de revés, sea en la casa, Esta noche juntos amándonos tanto y o en 1910, la Revolución Mexicana teatralizada, hito de la matria, la patria en femenino. Teatro de géneros diversos como las mujeres que lo escriben; y que atraviesa de lo romántico a lo realista, lo fantástico, lo trágico o surrealista y el absurdo: extraños y singulares híbridos, plenos de significados.

\section{DERECHO A LA HISTORIOGRAFÍA, A ESCRIBIR LA PROPIA HISTORIA}

Merolico: Señoras, señores, distinguido público, ipasen, pasen a ver el fenómeno más extraordinario del mundo: la Mujer que se volvió serpiente por desobediente...! (Castellanos, 1986:72)

Investigar la historia de la literatura escrita por mujeres, es una obligación de los estudios de género. Ya era una obligación feminista en los albores del siglo XX, para argumentar el voto femenino con sustento de historia contributiva. Las mujeres y el trabajo en fábricas, en el campo, la revolución agrícola; las mujeres en la guerra, enfermeras; en la casa, educadoras y formadoras de ciudadanos. Cuando Benito Juárez, el campeón del liberalismo mexicano, en la segunda mitad del siglo XIX, estableció las escuelas de niñas; las escuelas para señoritas; las de artes y oficios; las de obreras, precipitó la inquietud de las mujeres por los rumbos del conocimiento. Y surgieron los empleos en escuelas, para las maestras. Empleos bien vistos, especialmente para las solteras. A fines del XIX, durante durante las últimas décadas de Porifirio Díaz, se constituyó el sector docente, casi una clase social, "Las Señoritas Porfirianas (Ramos 1987: 143,) Las tareas de la reproducción social, ocupación asignada a "la mujer", imaginada como esencia femenina por el patriarcado, entraba en crisis. Con la educación formal, las mujeres salían del mundo doméstico y del sometimiento a esposos, padres, hermanos, hijos, sobrinos, para pugnar por la liberación, transformar las obligaciones impuestas de "la mujer para otros", salir de los cautiverios, como dijera Lagarde, para empezar a cultivar la autonomía personal.

Si formaban ciudadanía, ¿por qué no podrían ellas ser ciudadanas y formar a otras ciudadanas? Seguiría la urgencia política de ingresar a las universidades y alcanzar el sufragio femenino. Y con ello, el renovado interés en trazar nuestra historica como colectivo, con sentido genérico, y con fundamento en nuestros intereses, no como comparsas de los proyectos masculinos, no como "un gracioso cortejo" para los varones, como asegurara apenas hace dos décadas el historiador literario (Martínez 1984: 240)

La ceguera masculina ante lo femenino, la organización patriarcal del mundo, impedía ver las contribuciones de las mujeres al desarrollo, a la evolución; con ello se da 
la ignorancia de las cuestiones de género, de los géneros, --pero aquí interesa primero el femenino--. Por esa visión androcéntrica, binarista, casi bipolar, el género masculino llega a creer a pensar que lo que no sea masculino, falocéntrico, es femenino, asunto de mujeres, dicho despectivamente. Y como por siglos, la supremacía de los varones ha sometido a las mujeres, o ha privilegiado la sumisión femenina, lo masculino se define contra lo femenino, no ante lo femenino. De ahí que acabar con la invisibilidad de las mujeres en la historia sea una tarea urgente del feminismo y de los estudios de género, su vertiente académica. Pone fin a la estrecha visión de la división sexual del trabajo, lo público para los varones y lo privado, doméstico, para las mujeres, el derecho de las mujeres a esribir nuestra propia historia; el derecho a la historiografía.

Hace tiempo, casi al incorporarme al mercado de trabajo, me di cuenta, como profesora de literatura, del enorme salto en el recuento de las escritoras en México. La historia literaria mexicana escrita en el siglo $\mathrm{XX}$, --escrita por varones-- no encuentra escritoras. A pesar de que en los periodicos de la época, aquí y allá, se ven plumas femeninas; o se dan noticias de las tertulias y homenaje a las mujeres o de las mujeres.

Recuperar esta historia, rescatar del polvo del olvido a las escritoras y sus escrituras es ejercer el derecho a la historiografía, un ejercicio gozoso ${ }^{1}$. También es necesidad, pues escribir la propia historia lleva a valorar la propia vida. La autoestima, palabra nueva que denota el amor a lo propio, a la experiencia personal, es motivo para trazar la propia historia, conocer los orígenes. Dicen tanto el feminismo como los estudios de género, que la atoestima de las mujeres fundamenta la dignidad personal, sectorial, local y global, contra la extendida devaluación del sector femenino. "Hoy es cimiento de la identidad y conlleva el empoderamiento. La odiosa costumbre de la filiación patriarcal, ignora el linaje materno. $\mathrm{Y}$ en un caso como el mexicano, donde predomina la paternidad no asumida, al ecuperar el linaje y asumir la herencia se ejercen los derechos humanos de las personas y se atienden las necesidades propias. Tambien, se participa en procesos de seguridad, seguridad para una misma y la comunidad. El teatro, la escena, con el gran bagaje pedagógico de la dramaturgia se construyen ciudadanías; la catarsis, instrumento riquísimo de la teatralidad educa para la paz. En los escritos de estas mujeres se ven los procesos de liberación, personales, comunitarios, nacionales, desde tiempos prehispanicos.

Dicen historiadores actuales del teatro mexicano que, "los géneros dramáticos, históricamente, han sido un espacio permitido y aplaudido, para la autoría de las mujeres" (Madrigal y Ortiz 2012, II:9ss) y citan entre otros las investigaciones de Carlos González Peña, Jose Luis Martínez, Reyna Barrera y el compendio de Jacqueline Bixler

1 LGV, responsable del Proyecto de investigación "Historia documental de las mujeres en México", registrado en 1990, número 282, ante el Consejo de la División de Ciencias Sociales y Humanidades, de la Universidad Autónoma Metropolitana, Unidad Azcapotzalco en Ciudad de México. 
y Claudia Gilli, que es el más actual. Destacan también las creaciones de grandes personajes femeninos "el personaje mujer (que) constituye un elemento clave".

Cierto que en el mundo náhuatl no existió un género teatral deslindado del rito religioso, puede afirmarse - de acuerdo con las investigaciones de Fernando Horcasitas, Miguel León-Portilla y Garibay- que los ritos y la vida del mundo náhuatl en general estaba profundamente inmersa en un espíritu de teatralidad. Hoy día, el teatro prehispánico se vive en el cíclico Rabinal Achí, teatro danza de origen maya; obra maestra de la tradición oral e intangible de la humanidad².

$\mathrm{Su}$ origen, estrechamente vinculado con la religión, lo convierte en teatro-espejodel-hombre; un teatro que refleja como pocos "las raíces" de lo humano. Más que buscar la exaltación estética, este singular híbrido para la tradición occidental, producto original para sus creadores y escenificadores, intenta lograr conmover al público con la transferencia espiritual, emocional de la catarsis, para que el público, ante la intensidad de la representación, extraiga la fortaleza, la comprensión o resignacion para resistir, vivir, experimentar la fatalidad de la vida. El drama de entonces, que hoy persiste en las danzas tradicionales, mestizas, resignificadas de "Matanchines", de "Moros y Cristianos", enfatizan la temporalidad de los seres mortales, de todos nosotros. Así que esas obras de teatro incluían a la muerte como final de la representación. El teatro-rito náhuatl también buscaba, a través de la representación, un acercamiento a sus dioses, para comprender cómo el drama humano estaba influido por fuerzas cósmicas ajenas a su control. Danzas, cantos y representaciones, tal es la manifestación más antigua que se conoce en el mundo náhuatl. Aunque en primera instancia se efectuaba aisladamente, más tarde se incorporaron de manera definitiva a las acciones dramáticas que se representaban en honor a los dioses. En aquella expresión comunitaria, ritualistíca, las mujeres prehispanicas aparecían poco, apoyando proyectos masculinos, y eran más bien espectadoras. Con todo, en el teatro prehispánico, el cierre mortal, la muerte de los danzantes o guerreros o enmascarados precipitaba a actores y espectadores a otras dimensiones, a las otras vidas de las personas, a los otros mundos, inframundos o no, de las almas, y con ello, se abren ventanas al futuro, a vidas re-significadas, al recuento, como dijera Isabel Custodio, a los ciclos vitales, al eterno retorno que vuelve al origen tras la conflagración. Actualmente, el Rabinal Achi se sigue representando en el Sureste Mexicano, en los últimos días de enero, en torno al Dia de San Pablo, sincretismo existencial.

Al escribir la historia de la literatura náhuatl, dice el experto en el capítulo "Poesía dramática", que abundan los "fragmentos de melodrama, más que de cualquier otro

2 Unesco, 2005, inscrita en la Lista Representativa del Material Cultural Intangible de la Humanidad desde 2008; este singular hibrido de teatro de máscaras, danza, música data del siglo $\mathrm{XV}$ o antes, y de los tiempos en que la actual Guatemala formaba parte la Nueva España. 
género teatral" (Garibay 1992: 353) Si bien, antes de la Conquista española hubo otro tipo de actuaciones cómicas, divertimentos, representaciones festivas, tenían como único fin divertir al público y eran ejecutadas por titiriteros, juglares y magos y prestidigitadores. Esas escenificaciones ocurrían en las plazas, en los mercados y tianguis; en los corrales y patios traseros, huertas y haciendas.

En la época virreinal, tras el conflicto, tras la invasión y con el advenimiento de Occidente, surgieron en la Corte y en las casas representaciones de la vida social y familiar. Aquellas artes de juglares y magos o magas y saltimbanquies debieron haber seguido en las plazas, en las calles, en los mercados, aunque la arqueología nos brinda poca evidencia.

En concordancia con el Siglo de Oro Español, el teatro en Nueva España cruza el Atlántico y se instala lo mejor del Barroco, y no sólo La Verdad Sospechosa o Los Pechos Privilegiados, de Juan Ruiz de Alarcón. Sor Juana, al fin mujer, ocupa destacado lugar en "el espacio permitido y aplaudido para la autoría de mujeres" con medio centenar de piezas dramáticas: comedias, autos, sainetes, villancicos, loas. Como es sabido, Sor Juana sabía varios idiomas; escribía en español y en nahuatl, por la extraña y singular hibridez, el sincretismo o mestizaje de México y lo Mexicano. Cabe pensar que Sor Juana no fue la única escritora, la única dramaturga novohispana. Por aquella condición femenina, la opresión convertida en "cautiverios", según la categoría antropológica postulada por Marcela Lagarde, la escritura de mujeres permanecía en lo privado, en el círculo doméstico o conventual. Pero cabe pensar que tanto en la Corte como en el convento, hubo mujeres cultas, monjas, madresposas, que participaban en las ocasiones de celebracion de Nueva España, fiestas y saraos, bienvenidas a los virreyes, arcos triunfales y demás. Falta investigar en archivos privados. Por estos cautiverios, en la historia de la literatura mexicana escrita por varones, o por mujeres promotoras de los proyectos masculinos, hay un gran salto en la línea del tiempo. Pareciera como si las mexicanas nada hubieran escrito entre los tiempos de Sor Juana y los de María Enriqueta, salto de principios del XVII a principios del XX. ¿Sería que el estigma de descocadas e impuras caía sobre actrices y dramaturgas, aquello que Brianda Domecq con ironía llama, "Mujer que publica, mujer pública"? Ya se sabe la diferencia de sentido y de significado entre "hombre público" y "mujer pública".

Como se verá, en el siglo XIX, con los movimientos de Independencia, las escritoras van apoderandose poco a poco de la escena. He aquí a Isabel Prieto de Landázuri, de quien hablamos más adelante.

Llegado el siglo XX, tras las vanguardias, en 1900, 1910 y 1920, es el tiempo de las mujeres transgresoras: Pita Amor, Nahui Ollin, Maria Antonieta Rivas Mercado. Todas señoras ricas, grandes damas de sociedad. Pita Amor protagonista de escandalos de gran teatralidad, deambulaba semidesnuda por las calles de la Capital, ostentando su 
capacidad dramática, al igual que Nahui Ollin, mujer enigmática, diversa, tambien poseedora de máscaras y teatral. La Rivas Mercado, escritora interesante, se convierte en la gran impulsora del teatro, patrocinadora de la Compañía Ulises. Pero estas transgresoras, pioneras de la liberación sexual, primeras en desafiar los cautiverios, pronto encuentran la oposición masculina en la llamada "Polémica de la virilidad en literatura". De ellas, dice una dramaturga contemporánea, surgida en 1990ss:

La historia la han escrito los hombres y pocos de ellos han resaltado la participación femenina. Es hasta finales del siglo veinte y principios de éste donde ha habido intentos de estudiar y redescubrir la participación femenina, particularmente en la dramaturgia. (Leñero 2011:1)

Entre las que menciona están Magdalena Mondragón, Amalia Castillo Ledón, María Luisa Ocampo, Concepción Sada, y hay añadir a Catalina D'Erzell que escriben teatro costumbrista, cercano al melodrama, con tópicos domésticos familiares, en torno a problemas de honor y del matrimonio. A mediadios del siglo XX, tras la Revolución Mexicana y hacias las Guerras Mundiales, además de Frida Kahlo, nacen Elena Garro y Rosario Castellanos, y ya para 1975, Primer Año Internacional de la Mujer, aparece Maruxa Vilalta, de prolifica obra, la más longeva. Todas ellas deambulan por los espacios domésticos, en las casas y preocupaciones de mujeres, pero en todas sus obras puede verse, por las ventanas, hacia afuera, el drama de la nación: "mundo dual", lo llama Leñero:

La mujer mexicana vive en un mundo dual donde el desarrollo ideológico y cultural puede ser comparable al de un país del primer mundo, pero su realidad la enfrenta cotidianamente a un nivel de injusticia social y cultural evidentes. Para las mujeres dramaturgas, entonces, el escenario se convierte en un espacio de libertad y esperanza, de realidad y sueño, de experimentación y avance (Ibid)

Sigue ahora un análisis somero de las cuatro dramaturgas pioneras, las que abren los caminos para las escritoras del Tercer Milenio, las que apoderadas de la escena nacional representan la gama de intereses femeninos y feministas. Las dramaturgas del siglo XXI dotan de teatralidad a tópicos que antes, ni las señoritas porfirianas, ni sus hijas y nietas se atrevían a mencionas: desde el feminicidio a la menstruación, desde los males cardiacos a la violencia contra las mujeres. Sabina Berman aborda la escena global, desde lo local se precipita a intereses mundiales, con Entre Pancho Villa y una mujer desnuda, "Muerte súbita", Molière, Feliz nuevo siglo Doktor Freud, entre otras.

\section{DEL CORRAL DE COMEDIAS AL CORREDOR CULTURAL IBEROAMERICANO, ESCRITORAS Y ESCRITURAS DE AMBOS MUNDOS}


Malinche: Lo que yo crea no importa. No soy una vasalla de Moctezuma porque salí del poder del señor maya que le paga tributos. Ahora te pertenezco a ti.

Cortés: Te gusta el papel de diosa consorte, ¿eh?

Malinche: Me gusta que Moctezuma beba una taza de su propio chocolate. Es un amo cruel. (Castellanos 1987:90)

Los estudios trasatlánticos muestran la rica dinámica de intercambio cultural entre México y España, incluso después de 1810, de las guerras de Independencia. Para el mundo del teatro, considérense el estreno mundial en México de la emblemática obra de Iberoamérica, el Don Juan de José Zorilla; que sigue representandose como un eco en ambos mundos, claro ejemplo de las dinámicas ultramarinas. Por esta riqueza compartida entre España y la que fuera la Nueva España, surge en México, la dramaturgia de Isabel Prieto de Landázuri, primera literata objeto de un discurso de ingreso a la Academia Mexicana de la Lengua, correspondiente de la Real Española. Nació en España en 1833, y a los 3 años fue traida a México. Viviño y se desarrolló en la ciudad de Guadalajara, segunda en importancia a la Capital del país. Mujer culta, dama de la alta sociedad en Jalisco, comienza a publicar poemas en la adolescencia, y se casa con Pedro Landázuri, quien llegaría a ser gobernador del Estado y luego embajador en Alemania. Autora prolífica, Isabel escribe poesía y teatro. Pionera en la prensa decimonónica, sus poemas se publican en El Renacimiento y La Ilustración Mexicana, publicaciones periódicas de alcance nacional, forjadoras de la cultura mexicana, bastiones de la identidad nacional tras los 300 años de Colonia.

Suyo es el primer drama reconocido como escrito por una mujer en México, en 1861, Las dos flores.. En 1863, al triunfo de la República, restaurada por Benito Juárez tras la intervención francesa, Isabel estrenó en el Teatro Nacional, Un lirio entre zarzas. Isabel escribió 15 obras de teatro, como poetisa que era, la mayoría en verso. Recibió un homenaje en 1869, del Liceo Hidalgo, máxima institución literaria, sociedad que congregaba a los mejores escritores, los pioneros de los intelectuales mexicanos. Ella es la única que figura en el recuento de 1940, de Alfonso Reyes, uno de la generación de "Los 7 Sabios", XIX, quien en su historia literaria del XIX, dice que la menciona:

...no porque se ahoguen sus versos, como pudiera juzgarse al pronto, en aquella atmósfera artificial de "sensiblería" que a muchos parece la emanación espontánea del espíritu femenino, sino porque era Isabel Prieto, como se decía en los tiempos de Juan Jacobo, una mujer "interesante" y "sensible . (Reyes 1989: 173) 
En Las dos flores, drama que parece familiar, doméstico, el crítico actual encuentra "Poesía impregnada del más exquisito sentimiento romántico (donde...) el tema de la maternidad ocupa un sitio preponderante" (Rojo, 1990: 29 ) .Pero ahi donde el ojo masculino ve drama familiar, la experta con óptica de género descubre la fortaleza femenina ante la debilidad masculina. Dice la estudiosa del género que las mujeres llevan el protagonismo y al antagonismo en la escena, con lo cual Isabel se aleja del romanticismo y lo que ahora llamaríamos "cursilería", sentimentalismo excesivo imperante de la época; así, la autora rompe la tradicional debilidad femenina mientras que los personajes masculinos dudan, se atormenta,n y acaban por reconocer la supremacía de las damas ( Doria, 2012: 374 ). Con todo, la óptica de género permite la mirada bizca y el revés de la representacion. Este que parece drama doméstico es una alegoría de la patria, asediada por intruso que perturbe la tranquilidad de los esposos. Como México, asediado por los invasores franceses. La tension dramática es provocada por el mejor amigo del esposo que se enamora de la esposa; un extraño irrumpe en la armonía de la casa, invade el territorio. Las dos mujeres fuertes, la esposa y la prima se esfuerzan por enderezar la situación, y de paso, recuperar la paz doméstica. Ha habido tantas guerras y disturbios, rencillas y equivocos que la fuerza espiritual femenina se impone. La esposa convence al amigo de abandonar esa ilusión malsana y corresponder a la prima, que lo ama en secreto. Se restablece la paz en la casa, se restaura la República, vuelta a lo tradicional. Cuando Pedro Landazurí es nombrado embajador en Alemania, Isabel lo sigue, muere allá, en 1876.

Casi un siglo después, en 1974, Rosario Castellanos termina de escribir, poco antes de su muerte, otra historia nacional: El eterno femenino, farsa. Lupita, la protagonista, se va a casar, y en el proceso de despedirse de la soltería, repasa la historia de las mujeres mexicanas, y mientras la acicalan para la boda, desfilan ante ella mujeres célebres, desde la Malinche, a Sor Juana, Carlota, La Adelita. Lupita, una señorita mexicana post voto femenino, post liberación, cerca del Año Internacional de la Mujer, deambula pos los pasillos de su historia personal y nacional tratando de construir su identidad ante un "agente", la "peinadora" y un "animador" que la hostigan y tratan de confundirla. Pequeña pieza maestra, El eterno femenino es ya avanzada feminista como las demás obras de Castellanos, con un poco de crueldad suavizada por el humor inteligente que emerge de la ironía.

Tambien para dramatizar la patria en femenino, está la "fulgurante" Elena Garro, como la llama Beatriz Espejo, al enumerar la fuerza de la escritoras a fines del siglo XX:

Garro es quizás la mejor prueba, con sus ojos de niña traviesa y la originalidad de sus narraciones o piezas dramáticas, y Amparo Dávila y María Luisa Mendoza y Luisa Josefina Hernández y Guadalupe Dueñas y Esther Seligson y Brianda Domecq, dueña de una editorial dedicada al género, e Inés Arredondo que concebía cuentos espléndidamente urdidos, y Elena Poniatowska periodista sagaz, 
y Angeles Mastretta merecedora del premio Rómulo Gallegos, y Laura Esquivel que consiguió un bestseller a la altura de la globalización. (Espejo 2009: 86)

En el Centenario de su nacimiento, Elena Garro reaparece con su activismo, con su profunda conviccion de escritora y escritura de ahora y siempre: "En la única libertad que creo es en un espacio abierto, dentro de nosotras mismas, el único espacio libre que nos queda para soñar, pensar y crear" (Cit.por Rosas 2003: 10) . Gracias a su infatigable recopiladora, Patricia Rosas Lopategui, Garro que emigró despues del fatidico año de 1968 a España, en lo que llamó su "auto-exilio", ahora se dan cursos sobre su periodismo político, cultural; su narrativa; poesía; novelas; cuentos, teatro surrealista, el político ¿Quién recuerda ahora a Octavio Paz? , del que dice: “No me permitió terminar mis estudios, ni dedicarme a la danza, ni al teatro... papel tradicional de esposa". Como no podía actuar, se dedicó a escribir. "No me ocupaba mucho de cuando ponías mis obras, el que las llevaba al teatro era Octavio y no me permitía que yo metiera mano". Elena escribío solamente una tragedia, Felipe Angeles, en 1954, acerca del juicio fársico y el fusilamiento del general revolucionario traicionado por el Carrancismo, cuyos afanes de triunfo no toleran simpatizantes que puedan ser tanto o más poderosos por sus actos grandiosos. Drama histórico del hombre fuerte con un defecto de carácter, personaje shakesperiano que duda, que se debilita y pierde ante el embate de los traidores, drama de "Una nación que siempre mata a sus héroes":

Ángeles: ... Había demasiado odio, demasiada violencia acumuladacpor los siglos de injusticia. Habia miedo de perder lo ganado. Lo ganado nos volvió enemigos y la violencia fue nuestro único horizonte. ¿Por qué tuve horror de pelear por lo ganado? No lo sé. Pero tal vez si hubiera dado esa batalla se hubiera detenido esta cadena de crímenes. Cuando quise detener el horror y enseñar la concordia, mi muerte violenta prueba la ineficacia de mi acción y fortifica la violencia establecida... (Garro 2003: 69)

Mientras que el General desiste de la violencia, sus soldados, cobardes, huyen. Y las $\mathrm{Co}$-protagonistas son mujeres, damas de sociedad, que desean salvar al heroe del fusilamiento. El teatro como espejo de la vida, el revés de la vida, En su momento, la obra fue rechazada, imposible publicarla, imposible escenificarla. El partido en el poder, surgido del Carrancismo, no soportaba verse así reflejado. La tragedia de la patria, en escritura de la matria fue rescatada y recuperada en 1967; poco después Elena se autoexiliaba en España.

Cierra esta tetralogía la longeva Maruxa Vilalta, hija de un exiliado español, un notable de la II República Española de 1931, fundador del partido Esquerra Republicana, y de María Soteras Maurí, doctora en leyes, primera mujer que se recibió de abogada en la Universidad de Barcelona. Cuando empieza la guerra civil en España se exilian tres años en Bruselas y llegala familia a México vía Nueva York en 1939. Maruxa muy 
niña recibió la nacionalidad mexicana, pero conservó siempre sus raíces hispánicas, como se ve en los videos de la bibliografía. En 1960, empezó su carrera dramática y adaptó una novela suya a teatro. Siempre con preocupaciones sociales, su producción es enorme, variada, diversa, trasatlántica también. Exitosa en teatro, television y radio, en su larga carrera ganó más de 10 veces el premio de los críticos de teatro a la mejor obra del año. Las constantes en sus tematicas giran en torno a la imposibilidad humana de comunicarse, el afán de evasión de las personas, las parejas, los amantes. Pendiente de lo que sucedía en España, desde México dramatiza la crítica política, la suya devela una protesta contra la injusticia social y pregona la defensa del ser humano, la valía de las mujeres, de los varones, pero primero, de las mujeres. Activa hasta su muerte en 2014, para el Centenario de la Revoluciión Mexicana, escribe un drama histórico, 1910, sobre Emiliano Zapata, de nuevo, "una nación que fusila a sus héroes". Entre otras dramatizaciones de la matria, están: Una mujer, dos hombres y un balazo (1981); Pequeña historia de horror (y de amor desenfrenado) (1985); Una voz en el desierto. Vida de San Jerónimo (1991). Célebres son tambien, Esta noche juntos, amándonos tanto (1970); Nada como el piso 16 (1976); Historia de él (1978), Jesucristo entre nosotros (1994), Ignacio y los jesuitas (1997). En Un país feliz (1964), espejo de dos vistas, una en México, otra en España, pone en boca de uno de los protagonistas -“con ademanes exagerados de demagogo"-- la denuncia constante, la lucha por la justicia:

\footnotetext{
Santiago: Hay paises en donde la cosa es más complicada porque con el pretexto de dar garantías, protección al individuo, lo que se hace es retrasar la acción de la justicia. Aquí, por fortuna, no tenemos ese problema. Aquí la accion de la justicia es rápida y eficaz. El hombre dejado a su propio criterio está solo ante su destrucción. Es débil y no sabe gobernarse. Necesita de otro homber más fuerte para que lo dirija. En nuestrto país tenemos la suerte de tener un Jefe que piensa por nosotros y que se preocupa por la salvación de la patria. (Vilalta, 1997: 114)
}

En 2000, se proclamó de ella que poseía un lenguaje teatral propio, como la Garro.

Como Sor Juana.

Isabel, Rosario, Elena y Maruxa precedieron a las dramaturgas del Tercer Milenio, a las escritoras y escrituras con un cuarto propio: Berman y Leñero. Nueva Dramaturgia Mexicana nueva narrativa de revisiones históricas de mujeres. Prepararon el camino al teatro intervención feminista, con conciencia de género, organizacional para combatir la violencia contra las mujeres, de Rosalía Carrillo, de Amerika Moreschi o Carmen Trejo. Al dramatizar la violencia de género, al favorecer la catarsis y escenificar feminicidios, violaciones, mutilaciones de mujeres, se crea conciencia, se induce al repudio social y se construye la paz.

\section{REFERENCIAS BIBLIOGRÁFICAS}


Castellanos, R., El eterno femenino, farsa, México, Fondo de Cultura Económica, 1986

Custodio, I., Mujeres que cuentan, 7 escritoras mexicanas de su puño y letra, México, Ediciones, Ariadne, 2000

Domecq, B., Mujer que publica ... mujer pública, México, Editorial Diana, 1994

Espejo, B., Seis niñas ahogadas en una gota de agua: Pita Amor, Guadalupe Dueñas, Elena Garro, Rosario Castellanos, Amparo Dávila, Inés Arredondo, México, Universidad Autónoma de Nuevo León-Documentación de Estudios de Mujeres, 2009

Garibay, Á. M. K., Historia de la literatura náhuatl, México, Porrúa, 1992

Madrigal, E. y Ortiz Bulle Goyri, A., Mujeres en la dramaturgia mexicana, Tiempo y escritura, (junio de 2013, Volumen II), México, Universidad Autónoma MetropolitanaAzcapotzalco

Garro, E., Teatro, (edición y prologo) Patricia Rosas Lopategui, Albuquerque, Rosas Lopategui Publishing, 2003

Martínez, J. L., La expresión nacional, México, Oasis, 1984

Molina Enríquez, G. y Lugo Hubp, C., Mujeres en la historia, historias de mujeres. Una revisión de la historia de México a través de la participación de sus mujeres, México-La Jolla, California, USA, Ediciones Salsipuedes, 2009

Peña Doria, O. M., “El conflicto de género en Un lirio entre zarzas de Isabel Ángela Prieto de Landázuri, (Comp.) Sara Beatriz Guardia, Escritoras del Siglo XIX en América Latina, Perú, Centro de estudios la mujer en la historia de América Latina, CEMHAL, 2012

Ramos Escandón, C., "Señoritas porfirianas: mujer e ideología en el México progresista, 1880--1910", (coord.), Presencia y transparencia: la mujer en la historia de México, México, Programa Interdisciplinario de Estudios de la Mujer-El Colegio de México, 1987

Reyes, A., "Capítulos de la literatura mexicana”, Obras Completas T.I, , México, Fondo de Cultura Económica, 1989

Rojo, L., Teatro Mexicano, Historia y Dramaturgia XIX, Dramaturgas románticas (1861 -1885), México, Consejo Nacional para la Cultura y las Artes, 1995

Vilalta, M., Teatro I, México, Fondo de Cultura Económica, 1997, INTERNET

Leñero, E. "Dramaturgas mexicanas en dos tiempos" Siete Caminos Teatrales, Guanajuato ， Julio/2011 http://www.themagdalenaproject.org/sites/default/files/ Dramaturgas $\% 20$ mexicanas $\% 20$

Guanajuato.pdf, consultado en febrero de 2016 
Prieto Stambaugh, A. y Muñoz González, Y., “El teatro como vehículo de comunicación” , México, Editorial Trillas, cit. en Revista Raskkolnikov, gazzetta elettronica dell' Internet 05-02-2016,

(HTTP://REVISTARASKOLNIKOV.BLOGSPOT.MX/2008/05/TEATRO- INDÏGENAEN-MÉXICO.HTML)

YOUTUBE

Maruxa Vilalta habla de Un hombre una mujer dos balazos

- https://www.youtube.com/watch?v=qOXEPneWxrg Otra, ella misma

- https://www.youtube.com/watch?v=TqxczOd19Gg 